\title{
Congenital Lobar Emphysema: Perioperative Evaluation and Management
}

\author{
Montaser Elsawy Abd Elaziz, MD, ${ }^{1,2}$ Mohamed Gaber Elsayed, MS, ${ }^{2,3}$ Mohammed Ahmed El-hag-Aly, MD, ${ }^{1}$ \\ ${ }^{1}$ Cardithoracic Surgery Department, Faculty of Medicine, Menoufia University, Almenoufia, Egypt; \\ ${ }^{2}$ Faculty of Medicine, Jazan University, KSA; 3Al Anfoshy Pediatric Hospital, Alexandria, Egypt
}

\section{ABSTRACT}

Background: Congenital lobar emphysema (CLE) is a lung malformation characterized by overdistension and air trapping in the affected lobe. It is one of the causes of neonatal and infantile respiratory distress. This study aimed to evaluate our experience regarding perioperative and surgical management in children with CLE.

Methods: A retrospective observational study was done for all CLE patients who underwent surgery at Menoufia University Hospital. Perioperative data collected included demographic, clinical, and radiological findings, as well as operative and postoperative data.

Results: We included 30 neonates and infants who suffered from CLE between January 2013 and December 2020; the mean age was $111.43 \pm 65.19$ days, and 21 were males. All cases presented with respiratory distress; 19 had cyanosis, and 15 had recurrent pneumonia and fever. Plain chest x-ray and computed tomography (CT) revealed emphysema in all cases. Lobectomy was done in all cases; the mean age at surgery was $147.58 \pm 81.49$ days. Postoperative complications occurred in 5 patients, and 2 of them needed mechanical ventilation. The follow-up duration ranged from 3 months to 1 year (except 1 case lost to follow-up after 3 months), and all patients were doing well.

Conclusion: CLE is a rare bronchopulmonary malformation that requires a high index of clinical suspicion, especially in persistent and recurrent infantile respiratory distress. Chest CT is the most useful diagnostic modality. Early management of CLE improves outcome and prevents life-threatening complications. Surgical management is the treatment of choice in our center, without recorded mortality.

\section{INTRODUCTION}

Congenital lobar emphysema (CLE) is a rare developmental pulmonary anomaly that usually occurs due to aberrations in the development of lung parenchyma during the third week of gestation [Kerstine 2010]. CLE is defined as

Received March 20, 2021; received in revised form March 24, 2021; accepted March 25, 2021.

Correspondence: (e-mail: Montaser Elsawy Abd Elaziz, MD, Cardithoracic Surgery Department, Faculty of Medicine, Menoufia University, Egypt; (email: montaserabdelaziz7@gmail.com). overinflation of $\geq 1$ lung lobes due to partial obstruction of the bronchus, leading to pressure manifestations on the mediastinal structures [Olutoye 2000]. Most patients' symptoms appear during the first 6 months of life; half of patients have no clinical manifestations at birth. Ventilation and perfusion are usually impaired owing to hyperinflation of the diseased lobe, and with progressive hyperinflation, compression on the other lobe and mediastinal structures occurs [Mendeloff 2004; Paramalingam 2010].

Chest computed tomography (CT) is the cornerstone of diagnosis for CLE, as it allows assessment of the anatomy of both emphysematous and herniated lobes. Chest CT also is important in detecting whether the contralateral lung is hypoplastic. Contrast-enhanced CT is essential for diagnosis of vascular malformations and mediastinal masses [Karnak 1999; Markowitz 1989].

The management of patients with CLE depends on the severity of clinical manifestations. Half of patients have manifestations in the first months of life. Although a few asymptomatic patients have been described in previous studies, most cases are diagnosed in the first 6 months of life [Karnak 1999; Thakral 2001]. Conservative management is recommended in moderate cases, whereas severe cases are usually treated by lobectomy. Controversy regarding management is still present, especially if the manifestations of CLE are mild or moderate, for which some surgeons prefer conservative management and others prefer surgical intervention. But if there is severe respiratory distress, lobectomy is the treatment of choice [Mei-Zahav 2006; Ulku 2008].

We present our experience in the surgical management and follow-up of 30 cases admitted to our hospital.

\section{METHODS}

This is a retrospective observational study of 30 patients with CLE who were admitted for surgical management at the pediatric and cardiothoracic surgery departments, Menoufia University Hospital, Egypt, between 2013 and 2020. Their clinical presentation, diagnosis, treatment, and 6-month follow-up data were studied. The diagnosis of CLE was confirmed by clinical and radiological findings, in addition to histopathological examination. The parameters analyzed included age, clinical manifestations, chest $\mathrm{x}$-rays, and chest CT. All patients underwent lobectomy. Elective lobectomy was done in 24 cases, and emergency lobectomy in 6, because of respiratory distress. Postoperative data included need for mechanical ventilation, timing of oral feeding, clinical 
picture, analysis of radiological findings, and 6-month followup examination. Follow-up was done in outpatient clinics for all patients. The study was approved by Menoufia Faculty of Medicine Hospital ethics committee.

\section{Operative Technique}

General anesthesia via proper-sized single-lumen endotracheal intubation is induced, and excessive ventilatory pressures are avoided until the chest is opened. This precaution is necessary to avoid further expansion of the obstructed lobe and complication of remaining pulmonary function. A lateral position was used in all cases in this study, with a muscle-sparing posterolateral thoracotomy through the fourth intercostal space. The skin incision typically starts at the anterior axillary line just below the nipple level and extends posteriorly below the tip of the scapula. The incision then proceeds in a cranial direction halfway between the vertebral border of the scapula and the spinous processes of the vertebrae. The latissimus dorsi is divided, and the serratus anterior is retracted. Typically, at the fourth interspace the intercostal muscles are divided using electrocautery above the fifth rib. A rib spreader is placed into the thoracic cavity and minimally opened. Cautery can then be used to perform an internal thoracotomy by continuing the division of the intercostal muscles more anteriorly (up to the level of the internal mammary artery) and posteriorly (up to the level of the paraspinous tendons). The internal thoracotomy will prevent rib fracture during subsequent spreading of the retractor.

At thoracotomy, the emphysematous lobe is pale, spongy, and frequently prolapsed through the wound. It does not collapse and feels like a thickened sponge. The bronchus is soft, and the bronchial stump is closed by suture. Extrinsic causes, such as bronchial obstruction by an anomalous pulmonary artery, prehilar bronchogenic cyst, aneurysmal ductus arteriosus, or enlarged mediastinal nodes, should be excluded by careful mediastinal exploration before lobectomy. Before closure, it is necessary to test for air leak by saline. Usually, the anesthetist is asked to start manual ventilation to help inflate the residual lobe to fill the thoracic cavity. Two chest tubes are inserted, and the chest is closed in layers. Postoperative follow-up for 6 months in all cases is our practice to detect recurrence of manifestations or appearance of complications.

\section{Statistical Analysis}

Data were coded, entered, and analyzed using Microsoft Excel software. Data were then analyzed in Statistical Package for Social Sciences (SPSS version 20) software. Qualitative data are presented as number and percentage, and quantitative continuous groups are presented as mean \pm standard deviation (SD).

\section{RESULTS}

Of 30 patients with CLE, 21 were males and 9 were females. The mean age of onset of symptoms was $32 \pm 33.7$ days. Presenting features varied: tachypnea was present in all cases, dyspnea in 18 cases, cyanosis in 6 , fever in 15, failure to thrive in 3 , and irritability in 9 . Tachypnea, cyanosis, wheezing, and failure

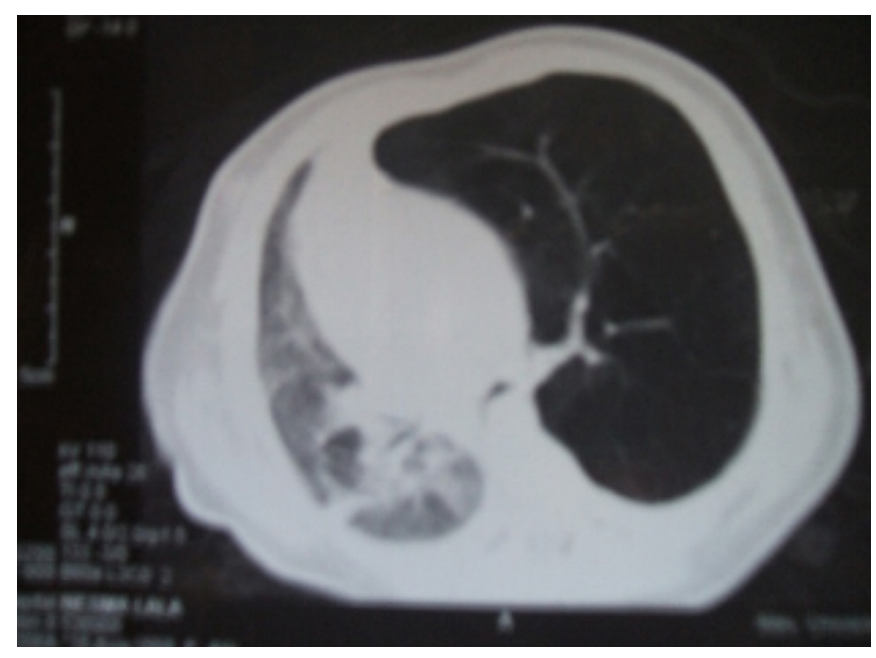

Figure 1. CT with contrast of the thorax shows massive hyperinflation of LUL, shift of the mediastinum to the right lung, and compression of the right lung.

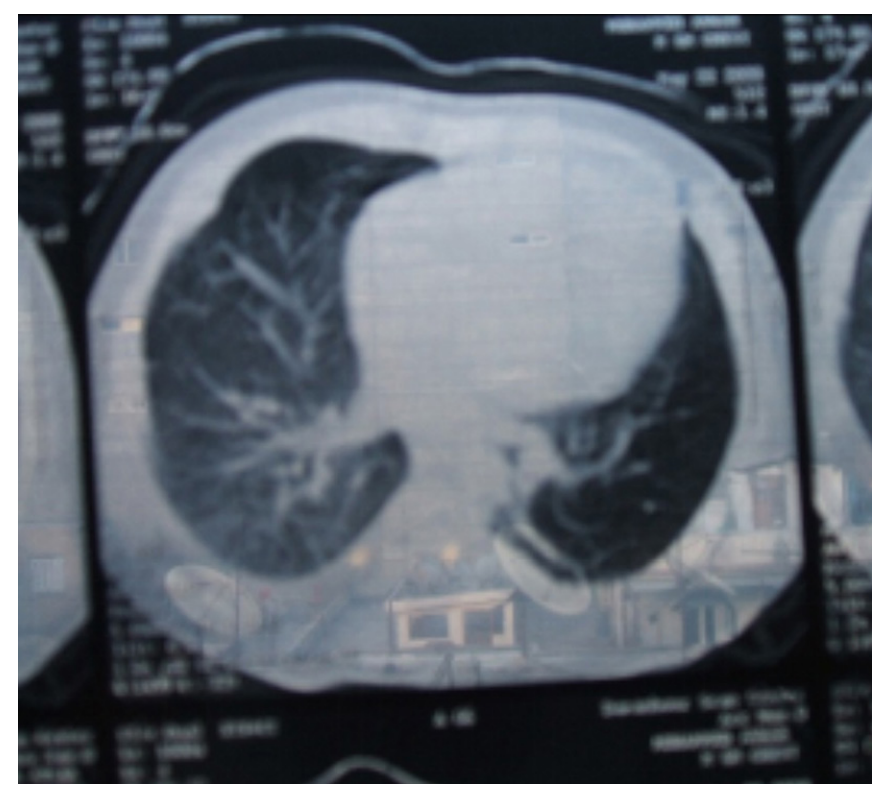

Figure 2. Postoperative CT of the same case demonstrates marked clearing of hyperinflation and herniation and right lung expanded.

to thrive were evenly scattered in all age groups, whereas cough, fever, and recurrent respiratory tract infection were significantly more common in older patients than younger ones. In contrast, dyspnea was more common in younger patients and correlated positively with bad general condition.

Fifteen cases presented with bad general condition (irritability, apneic spells, and neonatal reflex depression). Six cases needed assisted mechanical ventilation, and 12 needed mask oxygen; the remaining 12 cases were mildly symptomatic and able to maintain good oxygen saturation and blood gases on room air without oxygen supplementation. Arterial blood gas analyses revealed hypoxia in 18 cases and hypercapnia in 12 cases. 
Table 1. Preoperative Demographic and Clinical Features at Diagnosis $(n=30) *$

\begin{tabular}{lc}
\hline Variable & Value \\
\hline Age at presentation (d) & $32 \pm 33.7$ \\
Sex & $21(70)$ \\
Male & $9(30)$ \\
Female & \\
Symptoms & $30(100)$ \\
Tachypnea & $18(60)$ \\
Dyspnea & $6(20)$ \\
Cyanosis & $9(30)$ \\
Irritability & \\
Signs & $15(50)$ \\
Fever & $18(60)$ \\
Wheezes & $25(83.34)$ \\
Decreased breath sounds & $3(10)$ \\
Failure to thrive & \\
Arterial blood gases & $18(60)$ \\
Hypoxia & $12(40)$ \\
Hypercapnia & $6(20)$ \\
Assisted mechanical ventilation & $12(40)$ \\
Oxygen mask & $12(40)$ \\
No oxygen supplementation & $6(20)$ \\
Associated congenital heart disease & \\
\hline
\end{tabular}

*Data are mean \pm SD or $\mathrm{n}(\%)$.

A plain chest radiograph was done in all patients, with the following characteristic findings: increased translucency of affected side in 30 , mediastinal shift in 24 , herniation of overexpanded lung into contralateral side in 15 , and atelectasis in 15. CT of the thorax confirmed the findings of chest radiography and was beneficial in follow-up (Figures 1 and 2).

The left upper lobe (LUL) was affected in 24 cases, right middle lobe (RML) in 3, and right upper lobe (RUL) in 3. All patients underwent total lobectomy. Lobectomy was elective in 24 cases and emergency in 6 cases, due to severe respiratory distress. No postoperative oxygen supplement was required in 24 cases, whereas 3 cases needed assisted ventilation. Oral feeding was started on postoperative day 2 in 15 patients, day 3 in 9 , day 4 in 3 , and day 5 in 3 . Follow-up after 6 months revealed no complications in 24 cases, recurrent attacks of coughing in 3 , and recurrent respiratory tract infection in 3 .

\section{DISCUSSION}

The etiology of CLE is unknown in half of cases, and hyperplasia, dysplasia, or absent bronchial cartilage are
Table 2. Distribution of Studied Cases According to Radiological Findings

\begin{tabular}{lcc}
\hline Variable & $\mathrm{n}$ & $\%$ \\
\hline Findings & 30 & 100 \\
Increased translucency at affected side & 24 & 80 \\
Mediastinal shift & 15 & 50 \\
Herniation of overexpanded lung into contralateral side & 15 & 50 \\
Collapse of adjacent lobe & & \\
Affected lobe & 24 & 80 \\
LUL & 3 & 10 \\
RUL & 3 & 10 \\
RML & &
\end{tabular}

Table 3. Operative and Postoperative Follow-Up Data*

\begin{tabular}{|c|c|}
\hline Variable & Value \\
\hline Elective lobectomy & $6(80)$ \\
\hline Emergency lobectomy & $24(20)$ \\
\hline Operative time (min) & $142 \pm 21.5$ \\
\hline Postoperative mechanical ventilation & $3(10)$ \\
\hline \multicolumn{2}{|l|}{ Postoperative oral feeding begun } \\
\hline Day 2 & $15(50)$ \\
\hline Day 3 & $9(30)$ \\
\hline Day 4 & $3(10)$ \\
\hline Day 5 & $3(10)$ \\
\hline \multicolumn{2}{|l|}{ Symptoms } \\
\hline Cyanosis & $0(0)$ \\
\hline Tachypnea & $0(0)$ \\
\hline Dyspnea & $2(6.7)$ \\
\hline Cough & $2(6.7)$ \\
\hline \multicolumn{2}{|l|}{ Signs } \\
\hline Wheezes & $2(6.7)$ \\
\hline Decreased breath sounds & $2(6.7)$ \\
\hline \multicolumn{2}{|l|}{ Postoperative chest $\mathrm{x}$-ray } \\
\hline Normal & $27(90)$ \\
\hline Postoperative atelectasis & $2(6.7)$ \\
\hline Pneumothorax & $1(3.34)$ \\
\hline Mediastinal shift to opposite side & $0(0)$ \\
\hline \multicolumn{2}{|l|}{ 6-Mo follow-up } \\
\hline Well & $24(80)$ \\
\hline Recurrent cough & $3(10)$ \\
\hline Recurrent chest infections & $3(10)$ \\
\hline
\end{tabular}

*Data are mean \pm SD or $n(\%)$. 
indicated in a quarter of cases [Karnak 1999]. Acquired causes of CLE included meconium aspiration, hypertrophic mucous membranes, and foreign body aspiration [Michelson 1977; Aslan 2005]. Bronchogenic cysts and mediastinal tumors are considered rare extrinsic causes of CLE [Khemiri 2008; Kumar 2008].

CLE is a rare disease more common in males than females, at a ratio of 3:1 [Demir 2019], which was consistent with our study, in which the male:female ratio was $2.34: 1$, and a study by Cataneo et al [2013]. In our study, the age of patients ranged from 2 days to 5 months. The majority (70\%) presented within the first 6 weeks of life, as supported by Thakral et al [2001], in whose study $81 \%$ of the cases presented within the first 6 weeks of life, as well as Kunisaki et al [2019]. Delayed respiratory distress in children 5 years of age was reported by Man et al [1983]. Cataneo et al [2013] reported that delayed diagnosis of CLE was due to combined recurrent respiratory tract infections and respiratory distress in some patients in their study.

In the current study, CLE was diagnosed by clinical findings and confirmed by plain chest $\mathrm{x}$-ray, with atelectasis found in most cases. We confirmed the diagnosis by CT scan, also to discover other vascular anomalies. The diagnosis can be made prenatally by fetal ultrasound, but some cases may be missed and discovered later on during the postnatal period due to progressive overinflation of the emphysematous lobe that leads to pressure manifestations on mediastinal structures [Correa-Pinto 2010]. In our study, the LUL was most often involved, then RUL and RML. This finding is in agreement with the study done by Bush et al [2019]. Thacker et al [2014] also reported that the LUL was the most affected lobe followed by RUL and RML, whereas Berrocal et al [2004] reported that CLE was confirmed in lower lung lobes and bilateral lobes in some patients.

In our study, $100 \%$ of cases had hypertranslucency of the affected lobe, mediastinal shift to the opposite side was found in $80 \%$, and $50 \%$ had herniation of the affected lobe to the opposite side. Atelectasis was found in $50 \%$ of the cases, and no patient had pneumothorax. In a study conducted by Ozcelik et al. [2003], the radiological findings of 30 patients consisted of hyperlucency of affected lobe in $100 \%$, mediastinal shift to the opposite side in $52 \%$, atelectasis in $23 \%$, and pneumothorax in $4 \%$.

Our study incluced 6 cases (20\%) with associated heart anomalies by echocardiography, which must be routinely ordered preoperatively. Our finding was consistent with other studies [Mendeloff 2004; Bush 2019; Ozcelik 2003] that reported $14 \%$ to $20 \%$ of patients having congenital cardiac anomalies in association with CLE. These anomalies included patent ductus arteriosus, atrial septal defect, ventricular septal defect, and tetralogy of Fallot.

The standard surgical intervention in our study was lobectomy; lobectomy was also the standard management for other studies [Cataneo 2013; Perea 2017]. There is some controversy about whether to manage CLE patients conservatively or surgically, especially in mild clinical presentations; MeiZahav et al [2006] and Ceran et al [2010] prefer nonsurgical treatment in mild cases. Fierro et al [2018] discussed the decision in 6 cases with CLE, deciding that lobectomy was beneficial in such infants.

All our cases were operated via standard muscle-sparing posterolateral thoracotomy, which is our preferred approach in this age group and disease. The emphysematous lobe usually expands and occupies the whole thoracic cavity, which is managed with difficulty in thoracoscopy. Some authors who have used thoracoscopic lobectomy experienced difficulty and converted to thoracotomy [Rahman 2009; Zoeller 2018].

In a study conducted by Lincoln et al [1971], bronchial cartilage deficiency was found in $88 \%$ of cases, with no abnormal findings in $12 \%$. In our study deficiency of bronchial cartilage was found in $70 \%$ of cases, with no abnormal findings in the other $30 \%$. Approximately $20 \%$ of our patients had postoperative complications. Three cases suffered respiratory failure, needed mechanical ventilation, and were successfully weaned 3 to 4 days later; 2 patients had postoperative atelectasis; and 1 patient had pneumothorax.

Thakral et al [2001], in a 6-month follow-up of CLE cases, found $81 \%$ of the cases to be free of symptoms; $14 \%$ had recurrent attacks of respiratory tract infection, and $5 \%$ had recurrent attacks of coughing. In our follow-up at 6 months, no symptoms were found in $80 \%$ of the cases, $10 \%$ had attacks of cough, and $10 \%$ had recurrent respiratory tract infection.

No death occurred after 6 months of follow-up in our study. Ozcelik et al [2003] reported a survival rate of $88.5 \%$; in Lincoln et al [1971], 79\%; in Davis et al [1979], 88\%; and Nazem et al [2010], 87\%. Nazem et al [2010] referred to the number of affected lobes and base deficit at presentation.

\section{Limitations}

This study may be limited by the small number of patients and being retrospective in design.

\section{Conclusion}

Congenital lobar emphysema (CLE) is an important cause of respiratory distress in neonates and infants and should be put in the scope and mind of surgical practice. The diagnosis of CLE is established by combined evaluation of history, clinical examination, and radiological imaging and especially benefits from the accuracy of CT scan, the gold standard for diagnosis. CLE varies greatly in its presentation. The earlier the clinical presentation, the more severe the lesion and the greater the need for urgent surgical intervention. We emphasize that early surgical intervention (lobectomy) in mild and moderate disease is better than waiting for occurrence of complications. It is the appropriate treatment, and CLE is highly curable with lobectomy.

\section{REFERENCES}

Aslan AT, Yalcin E, Ozcelik, et al. Foreign-body aspiration mimicking congenital lobar emphysema in a forty-eight-day-old girl. Pediatr Pulmonol 2005;39:189-191.

Berrocal T, Madrid C, Novo S, et al. Congenital anomalies of the tracheobronchial tree, lung, and mediastinum: Embryology, radiology, and pathology. Radiographics 2004;24:e17. 
Bush A, Harcout J, Hewitt RJ, Nicholson AG. Congenital lung disease. In: Wilmott RW, Deterding R, Li A, et al., editors. Kendig's Disorders of the Respiratory Tract in Children. 9th ed. Philadelphia: Elsevier; 2019;321-322.

Cataneo DC, Rodrigues OR, Hasimoto EN, et al. Congenital lobar emphysema: 30-year case series in two university hospitals. J Bras Pneumol 2013;39:418-426.

Ceran S, Altuntas B, Sunam GS, et al. Congenital lobar emphysema: Is surgery routinely necessary? Afr J Paediatr Surg 2010;7:36-37.

Correia-Pinto J, Gonzaga S, et al. Congenital lung lesions underlying molecular mechanisms. Semin Pediatr Surg 2010;19:171-179.

Davis C, Lawrence J, Kenneth C, et al. Congenital lobar emphysema. South Med J 1979;72:696-698.

Demir OF, Hangul M, Kose M. Congenital lobar emphysema: Diagnosis and treatment options. Int J Chron Obstruct Pulmon Dis 2019;14:921-928.

Fierro JL, Hysinger EB, Piccione J, et al. The role of selective balloon occlusion in preoperative planning for infant pulmonary lobar hyperinflflation. Pediatr Allergy Immunol Pulmonol 2018;31:186-190.

Karnak I, Senocak ME, Ciftci AO, et al. Congenital lobar emphysema: Diagnostic and therapeutic considerations. J Pediatr Surg 1999;34:1347-1351.

Kerstine KH, Van Natta TL, Burkhart HM, et al. Congenital lung diseases. In: Sellke FW, Del Nido PJ, Swanson SJ, editors. Sabiston \& Spencer Surgery of the Chest. Vol. 1, 8th Ed. Philadelphia: Saunders Elsevier; 2010;129-150.

Khemiri M, Ouederni M, Ben Mansour F, et al. Bronchogenic cyst: An uncommon cause of congenital lobar emphysema. Respir Med 2008;102:1663-1666.

Kumar B, Agrawal LD, Sharma SB. Congenital bronchopulmonary malformations: A single-centre experience and a review of literature. Ann Thorac Med 2008;3:135-139.

Kunisaki SM, Saito JM, Fallat ME, et al. Current operative management of congenital lobar emphysema in children: A report from the Midwest Pediatric Surgery Consortium. J Pediatr Surg 2019;54:1138-1142.

Lincoln JC, Stark J, Subramanian S, et al. Congenital lobar emphysema. Ann Surg 1971;173:55-62.

Man DW, Hamdy MH, Hendry GM, et al. Congenital lobar emphysema:
Problems in diagnosis and management. Arch Dis Child 1983;58:709-712.

Markowitz RI, Mercurio MR, Vahjen GA, et al. Congenital lobar emphysema. The roles of CT and V/Q scan. Clin Pediatr (Phila) 1989;28:19-23.

Mei-Zahav M, Konen O, Manson D, et al. Is congenital lobar emphysema a surgical disease? J Pediatr Surg 2006;41:1058-1061.

Mendeloff EN. Sequestrations, congenital cystic adenomatoid malformations, and congenital lobar emphysema. Semin Thorac Cardiovasc Surg 2004;16:209-214.

Michelson E. Clinical spectrum of infantile lobar emphysema. Ann Thorac Surg 1977;24:182-196.

Nazem M, Hosseinpour M. Evaluation of early and late complications in patients with congenital lobar emphysema: A 12 year experience. Afr J Paediatr Surg 2010;7:144-146.

Olutoye OO, Coleman BG, Hubbard AM, et al. Prenatal diagnosis and management of congenital lobar emphysema. J Pediatr Surg 2000;35:792-795.

Ozcelik U, Göçmen A, Kiper N, et al. Congenital lobar emphysema: Evaluation and long-term follow up of thirty cases at a single centre. Pediatr Pulmonol 2003;35:384-391.

Paramalingam S, Parkinson E, Sellars M, et al. Congenital segmental emphysema: ;n evolving lesion. Eur J Pediatr Surg 2010;20:e78-e81.

Perea L, Blinman T, Piccione J, et al. Bilateral congenital lobar emphysema: Staged management. J Pediatr Surg 2017;52:1442-1445.

Rahman N, Lakhoo K. Comparison between open and thoracoscopic resection of congenital lung lesions. J Pediatr Surg 2009;44:333-336.

Thacker PG, Rao AG, Hill JG, et al. Congenital lung anomalies in children and adults current concepts and imaging findings. Radiol Clin $\mathrm{N}$ Am 2014;52:155-181.

Thakral CL, Maji DC, Sajwani MJ. Congenital lobar emphysema: Experience with 21 cases. Pediatr Surg Int 2001;17:88-91.

Ulku R, Onat S, Ozçelik C. Congenital lobar emphysema: Differential diagnosis and therapeutic approach. Pediatr Int 2008;50:658-661.

Zoeller C, Ure BM, Dingemann J. Perioperative complications of videoassisted thoracoscopic pulmonary procedures in neonates and infants. Eur J Pediatr Surg 2018;28:163-70. 